\title{
Effect of Compensation on Employee Performance: In Case of Mizan Tepi University Teaching Hospital
}

\author{
Walelign Gebito \\ Lecture, Department of Management, Mizan Tepi University, Ethiopia
}

\begin{abstract}
Compensation is very important for the performance of the employees. Therefore they are very important for the organization too. This study aimed to examine the effect of compensation on employee performance in Mizan Tepi University Teaching Hospital. The study was conducted from November 2018 to June 2019 and included all employees of the hospital. A questionnaire was designed to collect the data on the elements related to compensation like basic salary, bonus, house rent allowance, overtime policy, leave policy and employee performance. The study was used explanatory research design and both primary and secondary data was used to conduct this study. Stratified random sampling technique was used to infer the target population of the study. The data was collected from the employees of Mizan Tepi university teaching hospital. The collected data was analyzed by SPSS 20 Version. Descriptive and explanatory statistics was used to analyze the data and a sample of 213 employees was used to collect the data. However, only 200 employees responded to the questionnaires and hence, the response rate was 94 percent. Besides, descriptive statistical tools like frequency, percentage, mean and standard deviation are used to illustrate the demographic characteristics of the respondents and to assess the perception of employees from data collected through questionnaire and the study revealed that majority of the respondents feel disagreed on compensation elements of the organization. Inferential statistical methods like correlation analysis was used to assess the relationship between compensation elements and employee performance, multiple linear regression analysis also was employed to examine the influence of compensation elements on employee performance by using primary data collected through five scale likert questionnaire. Based on the findings of the study, all factors of employee performance have a positive and statistically significant correlation with employee performance. The multiple linear regression analysis (R2) implies that about $54.4 \%$ shows that compensation elements determine the variation of employee performance of Mizan Tepi university teaching hospital. Also the regression result revealed that all explanatory variables except bonus have a significant effect on employee performance. This indicated that compensation elements determine employee performance of Mizan Tepi university teaching hospital. Therefore, Mizan Tepi university teaching hospital should implement compensation elements appropriately and continuously as an indispensable tool to improve and maintain sustainable employee performance.
\end{abstract}

Keywords: employee performance, basic salary, bonus, house rent allowance, overtime policy and leave policy.

DOI: $10.7176 / \mathrm{EJBM} / 12-31-05$

Publication date: November $30^{\text {th }} 2020$

\section{INTRODUCTION}

Compensation is something that employees received as remuneration for their work. Compensation in the form of financial is important for the employees, because with the compensation they can directly fulfill their needs, especially the needs of physiology. However, the employees must also hope that it receives compensation in accordance with the sacrifice that has been given in the form of nonfinancial also very important for the employees especially for their career development (Mwangi, 2014).

Compensation program help to maintain an organization human resource, when wage and salaries are not administered properly, the firm may lose employees and the money spent to recruit, select and develop them. Compensation disparities together with their consequences had been an economic research topic for long. Where as many papers focus on in description of the development of compensation differences overtime and seek identification of the reasons for observed patterns.

\subsection{Objective of the study}

The study was both general and specific objectives

\subsubsection{General objective}

The general objective of this study was to examine the effect of compensation on employee performance in Mizan Tepi university teaching hospital.

1.2.2 Specific objectives

The specific objectives of this study were as the following;-

$>$ To investigate the relationship between compensation elements and employee performance of Mizan Tepi university teaching hospital.

$>$ To determine whether basic salary has significant effect on employee performance in Mizan Tepi university teaching hospital. 
$>$ To identify whether bonus has significant effect on employee performance in Mizan Tepi university teaching hospital.

$>$ To examine whether house rent allowance has significant effect on employee performance in Mizan Tepi university teaching hospital.

$>$ To find out whether overtime policy has significant effect on employee performance in Mizan Tepi university teaching hospital.

$>$ To investigate whether leave policy has significant effect on employee performance in Mizan Tepi university teaching hospital.

\subsection{Research Hypothesis}

Ho1: basic salary has no significant effect on employee performance in Mizan Tepi university teaching hospital.

Ho2: bonus has no significant effect on employee performance in Mizan Tepi university teaching hospital.

Ho3: house rent allowance has no significant effect on employee performance in Mizan Tepi university teaching hospital.

Ho4: overtime policy has no significant effect on employee performance in Mizan Tepi university teaching hospital. Ho5: Leave Policy has no significant effect on employee performance in Mizan Tepi university teaching hospital.

\section{RETERATURE REVIEW}

\section{Human capital theory}

Human capital signifies the combined the brainpower and experience of staff as a source of competitive improvement that cannot be imitated by rivals (Resick, 2007). This theory advocates for attracting, engaging, repayment and developing people in organizations. In the context of Agriculture and business sector. Some of the employee compensation practices in this research are meant to ensure that the performance of employees is improved this theory is relevant. However this theory has been criticized for not addressing other underlying components of employee performance. Scholars have argued that ultimately, it's only the characteristics that improve employee performance. This is because it considers reward which is also a factor of compensation. This means that employees can be rewarded for their efforts despite the fact that the theory does not examine the effect of the rewards.

\section{Expectancy Theory}

According to Armstrong (2010). in the expectancy theory, motivation is likely to be when there is a perceived and usable relationship between and outcome, with the outcome being seen as a means of rewarding needs. In other words, there must be a relationship between a certain reward and what has to be done to achieve it. This theory is very important in the context of this research. It is instrumental especially when designing performance-based employee wellbeing programms. This theory helps explain why an organization's staff would feel confident that they can grow in the same organization, hence remain there, or seek development elsewhere by exiting the organization.

\section{Figure 1 Conceptual Framework}

Independent variables

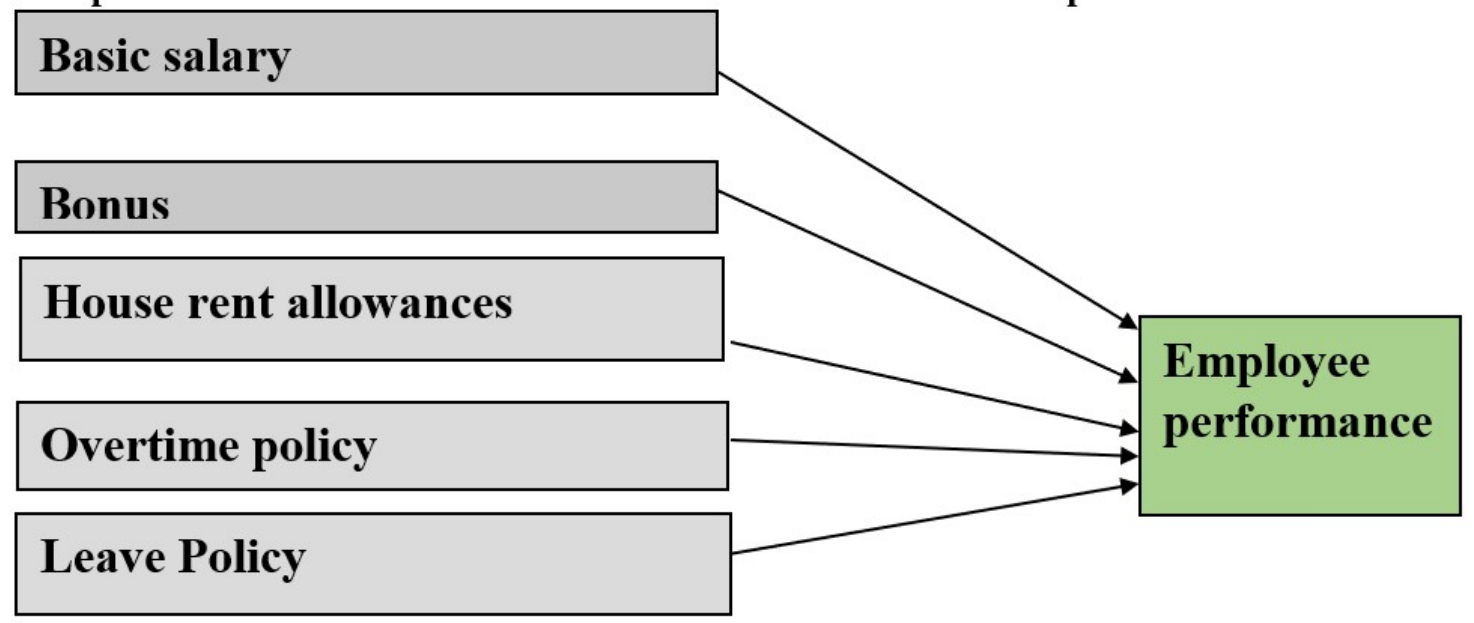

Source; adopted by Catherine nkatha kabiru 2018 \& researcher 2018

\section{RESERCH METHDOLOGY}

Under this study the explanatory research design was used shows the effects of compensation element: basic salary, house rent allowance, overtime policy and leave policy on employee performance, quantitative approach and cross sectional survey was utilized under this study. 
Both primary and seconder source of data were used under this study, the instrument used for data collection for in this study is the questionnaire, the target population of the study was the employees of Mizan Tepi university teaching hospital. The total numbers of the employee are 476 employee are found in the hospital, this study was used stratified random sampling technique, the strata's are including three categories of employee: administrative staff, clinical staff and support staff.

Data was be fed into SPSS (statistical package for social science) was used to analyze collected data for easy analysis, sorting and coding of data was done and both descriptive statistics and inferential statics was used in data analysis and multiple leaner regression model was used under this study.

$$
\mathrm{Y}=\beta \mathrm{o}+\beta 1 \mathrm{X} 1+\beta 2 \mathrm{X} 2+\beta 3 \mathrm{X} 3+\beta 4 \mathrm{X} 4+\beta 5 \mathrm{X} 5+\varepsilon
$$

\section{DATA PRESENTATION, ANALYSIS AND INTERPRETATION}

Five Scaled Likert Criterion

\begin{tabular}{|l|l|l|}
\hline No. & Mean range & Response Option \\
\hline 1 & 1 to 1.80 & Strongly disagree \\
\hline 2 & 1.8 to 2.6 & Disagree \\
\hline 3 & 2.6 to 3.4 & Neutral \\
\hline 4 & 3.4 to 4.20 & Agree \\
\hline 5 & 4.2 to 5.00 & Strongly Agree \\
\hline
\end{tabular}

Source: Al-Sayaad et al. (2006), as cited by Bassam, 2013).

\section{Summary of descriptive analysis}

No Compensation Elements

1 Basic salary

2 Bonus

3 House rent allowance

$4 \quad$ Leave policy

$5 \quad$ Overtime policy

$6 \quad$ Employee performance

Source; (filed Survey, 2019).

\section{The relationship between variables}

Correlation is a statistical technique used to determine the degree to which two variables are related. Correlation coefficient shows the relationship between the dependent and independent variables. In this study Pearson correlation analysis was utilized.

Correlation means relationship between two variables. It measures the degree to which two sets of data are related. Higher correlation value indicates stronger relationship between both sets of data (Coetzee, 2003). Correlation Analysis is to show the strength of the association between the variables involved. Inter-correlations coefficients (r) were calculated by using the Pearson's Product Moment. The output of correlation matrix can be the correlation coefficient that lies between -1 and +1 within this framework, a correlation coefficient of +1 indicates a perfect positive relationship, and a correlation coefficient of -1 indicates a perfect negative relationship; whereas a coefficient of 0 indicates no liner relationship. Moreover, the two variables are casually related which means that one of the variables is independent and the other one is dependent; and a large number of independent causes are operating in both variables so as to produce a normal distribution (Kothari, 2004). Stating only the relationship is not enough as it may involve both dimensions from zero (negative, zero itself, or positive). Therefore, to know the strength and type of correlation between variables, the following table is set as a rule of thumb for discussion of this study.

Rule of Thumb for about the Strength of Correlation Coefficients

\begin{tabular}{|l|l|}
\hline Range of Coefficient & Description of Strength \\
\hline \pm .81 to \pm 1.00 & Very strong positive (negative) correlation \\
\hline \pm .61 to \pm .80 & Strong positive (negative) correlation \\
\hline \pm .41 to \pm .60 & Moderate positive (negative) correlation \\
\hline \pm .21 to \pm .40 & Weak positive (negative) correlation \\
\hline \pm .00 to \pm .20 & None \\
\hline
\end{tabular}

Source: Bhattacherjee (2012)

Therefore, using the above table 4.9 and the SPSS output of the survey, the blow results of the dependent variable employee performance and the independent variables basic salary, bonus, house rent allowance, overtime policy and leave policy are going to be discussed in detail basis. 


\begin{tabular}{|c|c|c|c|c|c|c|c|}
\hline \multicolumn{8}{|c|}{ Correlations } \\
\hline & & $\begin{array}{l}\text { Basic } \\
\text { salary }\end{array}$ & Bonus & $\begin{array}{l}\text { House } \\
\text { allowance }\end{array}$ & $\begin{array}{l}\text { rent Overtime } \\
\text { policy }\end{array}$ & $\begin{array}{l}\text { Leave } \\
\text { policy }\end{array}$ & \begin{tabular}{|l} 
Employee \\
performance
\end{tabular} \\
\hline \multirow[t]{3}{*}{ Basic salary } & \begin{tabular}{|l} 
Pearson \\
Correlation
\end{tabular} & 1 & & & & & \\
\hline & Sig. (2-tailed) & & & & & & \\
\hline & $\mathrm{N}$ & 200 & & & & & \\
\hline \multirow[t]{3}{*}{ Bonus } & $\begin{array}{l}\text { Pearson } \\
\text { Correlation }\end{array}$ & $391^{* *}$ & 1 & & & & \\
\hline & Sig. (2-tailed) & .000 & & & & & \\
\hline & $\mathrm{N}$ & 200 & 200 & & & & \\
\hline \multirow[t]{3}{*}{$\begin{array}{l}\text { House } \\
\text { allowance }\end{array}$} & $\begin{array}{l}\text { Pearson } \\
\text { Correlation }\end{array}$ & $.353^{* *}$ & $.488^{* *}$ & 1 & & & \\
\hline & Sig. (2-tailed) & .000 & .000 & & & & \\
\hline & $\mathrm{N}$ & 200 & 200 & 200 & & & \\
\hline \multirow[t]{3}{*}{ Overtime policy } & $\begin{array}{l}\text { Pearson } \\
\text { Correlation }\end{array}$ & $.372^{* *}$ & $.458^{* *}$ & $.647^{* *}$ & 1 & & \\
\hline & Sig. (2-tailed) & .000 & .000 & .000 & & & \\
\hline & $\mathrm{N}$ & 200 & 200 & 200 & 200 & & \\
\hline \multirow[t]{3}{*}{ Leave policy } & \begin{tabular}{|l|} 
Pearson \\
Correlation
\end{tabular} & $.441^{* *}$ & $.511^{* *}$ & $.624^{* *}$ & $.539^{* *}$ & 1 & \\
\hline & Sig. (2-tailed) & .000 & .000 & .000 & .000 & & \\
\hline & $\mathrm{N}$ & 200 & 200 & 200 & 200 & 200 & \\
\hline \multirow[t]{3}{*}{$\begin{array}{l}\text { Employee } \\
\text { performance }\end{array}$} & \begin{tabular}{|l|} 
Pearson \\
Correlation
\end{tabular} & $.412^{* *}$ & $.430^{* *}$ & $.673^{* *}$ & $.615^{* *}$ & $.581^{* *}$ & 1 \\
\hline & Sig. (2-tailed) & .000 & .000 & .000 & .000 & .000 & \\
\hline & $\mathrm{N}$ & 200 & 200 & 200 & 200 & 200 & 200 \\
\hline
\end{tabular}

Source: (filed survey, 2019)

\section{The relationship between basic salary and employee performance}

According to the above table 4.10, there is a significant positive relationship between basic salary and employee performance $(\mathrm{r}=.412, \mathrm{p}<0.01)$. According to Bhattacherjee the magnitude of correlation, there is moderate and positive relationship between basic salary and employee performance. This finding was consistent with Awasthi and Pratt (2010) study which found a significant result on their hypothesis that monetary incentive are positively related to time spent on decision, also the study was concur with Catherine (2018) study which found that there is significant relationship between salary and employee performance.

\section{The relationship between bonus and employee performance}

The above table 4.10 was show there is a significant positive relationship between bonus and employee performance $(r=.430, p<0.01)$. According to Bhattacherjee (2012) the magnitude of correlation, there is moderate and positive relationship between bonus and employee performance. The finding of this study concur with Pergamit and Veum (2010) study on effects of bonuses on employee performance which found that there is a positive correlation between bonus and employee performance, also the study was consistent with Catherine (2018) study which found that there is significant relationship between bonus and employee performance.

The relationship between house rent allowance and employee performance

According to the above table 4.10, there is a significant positive relationship between house rent allowance and employee performance $(r=.673, \mathrm{p}<0.01)$. According to Bhattacherjee (2012) the magnitude of correlation the relationship between the variables were strongly positive. There is strongly positive relationship between house rent allowance and employee performance because of the positive value for correlation coefficient. When the house rent allowance is high, employee performance is also high. The positive correlation means house rent allowance result in increasingly positive employee performance. This finding was consistent with Awasthi and Pratt (2010) study which found a significant result on their hypothesis that monetary incentive are positively related to time spent on decision.

\section{The relationship between overtime policy and employee performance}

According to the above table 4.10 , there is a significant positive relationship between overtime policy and employee performance $(\mathrm{r}=.615, \mathrm{p}<0.01)$. According to Bhattacherjee (2012) the magnitude of correlation the relationship between the variables were strongly positive. There is strongly positive relationship between overtime policy and employee performance because of the positive value for correlation coefficient. Hence, when the 
overtime policy is high, employee performance is also high. The positive correlation means overtime policy in increasingly positive employee performance. The finding of this study concur with Odunlami and Matthew (2014) and study by Nelson and Gary (2012) non-monetary compensation were strongly positively correlation with employee performance.

The relationship between leave policy and employee performance

From the above table 4.10, there is a significant positive relationship between leave policy and employee performance $(r=.581, \mathrm{p}<0.01)$. According to Bhattacherjee (2012) the magnitude of correlation, there is moderate and positive relationship between leave policy and employee performance. The finding results of this study consistence with Odunlami and Matthew (2014) and study by Nelson and Gary (2012) non-monetary compensation were strongly positively correlation with employee performance.

Summary: based on the above five correlation analysis the hypothesis is called either significant relationship between compensation elements and employee Performance. Is answered. Therefore, all of five elements of compensation have a significant relationship with employee performance. With regard to the magnitude of the correlation, five elements (basic salary, bounce, house rent allowance, overtime policy and leave policy) have positively correlation with employee performance.

Regression Analysis of the Study

Results showing coefficient of regression analysis

\begin{tabular}{|c|c|c|c|c|c|}
\hline \multicolumn{6}{|c|}{ Coefficients a } \\
\hline \multirow[t]{2}{*}{ Independent Variables } & \multicolumn{2}{|c|}{$\begin{array}{c}\text { Unstandardized } \\
\text { Coefficients }\end{array}$} & $\begin{array}{c}\text { Standardized } \\
\text { Coefficients }\end{array}$ & $\mathrm{T}$ & Sig. \\
\hline & B & Std. Error & Beta & & \\
\hline (Constant) & .302 & .249 & & 1.210 & .228 \\
\hline Basic salary & .120 & .058 & .115 & 2.068 & .040 \\
\hline Bonus & .010 & .055 & .011 & .186 & .853 \\
\hline House rent allowance & .387 & .075 & .369 & 5.174 & .000 \\
\hline Overtime policy & .254 & .071 & .239 & 3.587 & .000 \\
\hline Leave policy & .157 & .064 & .165 & 2.436 & .016 \\
\hline
\end{tabular}

\section{Interpretation:}

Source: (filed survey, 2019)

Keeping all other variables Constant;

- For every one-unit increment on basic salary, the percentage of employee performance increases by 12.0 (percent).

- For every one-unit increment on house rent allowance, the percentage of employee performance increases by 38.7 (percent).

- For every one-unit increment on overtime policy, the percentage of employee performance increases by 25.4 (percent).

- For every one-unit increment on leave policy, the percentage of employee performance increases by 15.7 (percent).

The model of employee performance can be written by including error term $(\varepsilon)$ as:

Employee performance $=.302+.120$ basic salary +.387 house rent allowance +.254 overtime policy +.157 leave policy +.249

Interpretation:

- A 1 standard deviation increase in standardized basic salary is predicted to result in 0.115 standard deviation increase in standardized employee performance holding constant the remaining variables.

- A 1 standard deviation increase in standardized house rent allowance is predicted to result in 0.369 standard deviation increase in standardized employee performance holding constant the remaining variables.

- A 1 standard deviation increase in standardized overtime policy is predicted to result in 0.239 standard deviation increase in standardized employee performance holding constant the remaining variables.

- A 1 standard deviation increase in standardized leave policy is predicted to result in 0.165 standard deviation increase in standardized employee performance holding constant the remaining variables. 


$\begin{array}{llll}\begin{array}{l}\text { Summary of hypothesis test result } \\ \text { No }\end{array} \begin{array}{l}\text { Hypothesis } \\ \text { Basic salary has statistically significant effect on the employee } \\ \text { performance of Mizan Tipe university teaching hospital. }\end{array} & \begin{array}{l}\text { Tool } \\ \text { Regression }\end{array} & \begin{array}{l}\text { Result } \\ \text { Accepted }\end{array} \\ \text { Ha2 } & \begin{array}{l}\text { Bonus has statistically significant effect on the employee performance } \\ \text { of Mizan Tipe university teaching hospital. }\end{array} & \text { Regression } & \text { Rejected } \\ \text { Ha3 } & \begin{array}{l}\text { House rent allowance has statistically significant effect on the } \\ \text { employee performance of Mizan Tipe university teaching hospital. }\end{array} & \text { Regression } & \text { Accepted } \\ \text { Ha4 } & \begin{array}{l}\text { Overtime policy has statistically significant effect on the employee } \\ \text { performance of Mizan Tipe university teaching hospital. }\end{array} & \text { Regression } & \text { Accepted } \\ \text { Ha5 } & \begin{array}{l}\text { Leave policy has statistically significant effect on the employee } \\ \text { performance of Mizan Tipe university teaching hospital. }\end{array} & \text { Regression } & \text { Accepted }\end{array}$

Source :( filed survey, 2019)

\section{SUMMARY, CONCLUSION, AND RECOMMENDATIONS Summary of Major Findings}

Based on the analysis results of the study the following summaries are made accordingly:

Based on the demographic information of the respondents, figure 4.1 illustrates majority of the respondents 55 (percent) were females and the remaining 45 (percent) were males and figure 4.2 indicates majority of the respondents were youngster 30 (percent) were found in 31-40 age group and 26.5 (percent) were found below the age of 30. As figure 4.3 illustration of marital status majority of the respondents 52.5 (percent) were married and 47.5 (percent) were single. Based on figure 4.4 illustration majority of the respondents 49.5 (percent) were clinical staff, 26.5(percent) were supportive staff, 24.5(percent) were administrative staff and figure 4.5 indicates majority of the respondents 32 (percent) were 4-5 years duration in their working position and 25.5 (percent) were 6- 10 years they held in their working position. From the figure 4.6 illustration majority of the respondents 54.5 (percent) were bachelor degree holders, 25.5 (percent) were diploma holders. Moreover, figure 4.7 indicates majority of the respondents 48.5 (percent) were monthly salary between 3001-5000birr and 29.9 (percent) were between 1501-3000 birr.

From the analysis result of descriptive statistics of the study, majority of the respondent were disagreed about compensation that paid by the organization (basic salary, bonus and house rent allowance) and they agreed on overtime policy and leave policy of the organization. Moreover, the findings from the descriptive statistics on employee performance indicate that majority of the employees were disagreed with their performance.

Also the result of Pearson correlation five independent variables i.e. basic salary, bonus, house rent allowance, overtime policy and leave policy are positive and statistically significant relationship with the dependent variable i.e. employee performance at 99 percent confidence level $(\mathrm{P}<0.01)$. The highest correlation is signified by house rent allowance $(r=0.673)$, overtime policy $(r=0.615)$, leave policy $(r=0.581)$, bonus $(r=0.430)$ and basic salary $(r$ $=0.412$ ).

The analysis result of multiple linear regression of the five compensation elements. The table result shows that the model test is significant with the R Square value of 0.544 (54.4 percent), it indicates that the variability of the employee performance of Mizan Tepi university teaching hospital explained by the variability of independent variables i.e. basic salary, bonus, house rent allowance, overtime policy and leave policy while, the remaining 45.6(present) of the variability of the employee performance of Mizan Tepi university teaching hospital may be explained by other factors.

From the coefficients of compensation elements. Thus on the other hand, the Beta coefficient for basic salary (X1) is $\beta 1=0.120$ indicates the growth of the employee performance up to 0.120 on average by keeping the other variables constant, the Beta coefficient for bonus (X2) is $\beta 2=0.010$ indicate the growth of the employee performance up to 0.010 on average by keeping the other variables constant, the Beta coefficient for house rent allowance $(\mathrm{X} 3)$ is $\beta 3=0.387$ indicate the growth of the employee performance up to 0.387 on average by keeping the other variables constant, when the Beta coefficient for overtime policy (X4) is $\beta 4=0.254$ indicates the growth of the employee performance up to 0.254 on average by keeping the other variables constant and the Beta coefficient for leave policy (X5) is $\beta 5=0.157$ indicate the growth of the employee performance up to 0.157 on average by keeping the other variables constant as the model shows clearly, the majority of the contribution to the employee performance is occupied by house rent allowance.

The analysis results of multiple linear regressions of the five compensation elements, the p-value of each 
hypothesis should be either accepted or rejected with reference to 5 (percent) level of significance; i.e. the null hypothesis must be rejected if P- value is less than 0.05 other wise accept it. Based on this four independent variables (basic salary, house rent allowance, overtime policy and leave policy) have statistically significant effect on the employee performance of Mizan Tepi university teaching hospital with a P-Value of 0.040, 0.000, 0.000 and 0.016 respectively (Reject Ho if $\mathrm{p}<0.05$ ). Furthermore, one independent variable (bonus) has no statistically significant effect on employee performance of Mizan Tepi university teaching hospital with a p-value of 0.853(Accept Ho if $\mathrm{P}>0.05$ ).

\section{Conclusion}

During the investigation the researcher used both descriptive and inferential statistics and based on the findings of the research the researcher made conclusions by outlining following points.

As the results of the descriptive statistics depicted most of the employee were disagreed with the compensation elements (basic salary, bonus and house rent allowance), while they agreed on overtime policy and live policy \& practices of the organization. As some of the respondent's responses tends in to neutral. This implies that the employees are working with pleasure in terms of basic salary, bonus, house rent allowance, overtime policy and leave policy (compensation elements) practices of the organization.

Five determinant factors of employee performance have a positive and statistically significant correlation with employee performance. The correlation between the dependent variable employee performance and the five independent variables was with magnitude ranges of "moderate and positive" (3), and "strongly positive" (2) level of correlation.

The pre-model fitting six assumptions (i.e., sample size, normality of distribution, linearity, multi collinearity of the variables, independence of residuals and homoscedasticity) of multiple regressions are met accordingly. Furthermore, the multiple linear regression analysis (The R square) implies that about 54.4 (percent) shows that the five compensation element (basic salary, bonus, house rent allowance, overtime policy and leave policy) can determine the variation of the employee performance of Mizan Tepi university teaching hospital. Therefore, the researcher can convincingly conclude that the compensation elements has a significant influence on employee performance of the organization.

As far as the relative effects of an individual elements of compensation elements on employee performance is concerned, the result of multiple linear regression coefficient shows that house rent allowance has the highest beta value which indicates the most dominant effect in determining the variation of employee performance followed by overtime policy with a beta values of $(\beta 1=0.387 \& \beta 2=0.254)$ respectively.

The multiple linear regression analysis of the independent variables and dependent variables shows that four of five explanatory variables (basic salary, house rent allowance, overtime policy, and leave policy) have a statistically significant effect for predicting employee performance of Mizan Tepi university teaching hospital. The remaining one (bonus) has no statistically significant effect on employee performance.

\section{Recommendations}

This study has demonstrated that the effect of compensation on employee performance in Mizan Tepi university teaching hospital. In light of the findings and conclusions made above, the following possible recommendations are suggested as being valuable to the organization for improving the employee performance.

The organization practices of compensation elements (basic salary, house rent allowance, overtime policy and leave policy) have to be enhanced in order to increase employee performance. This can be enhanced and developed through the following:

$>$ Mizan Tepi university teaching hospital and Ministry of Health should consider reviewing the salary pay on a yearly basis. These will help in keeping the employee in the company for long and enhancing their loyalty as well as improve their performance.

$>$ House rent allowance are not paid for all of the employees that found in all working place of the organization so the study recommend that the organization pay house rent allowance for all of the employee fairly because of the employee who don't paid house rent allowance properly has demotivated and perform less than the standard.

$>$ The study recommends that organization consider finding a way of paying bonuses based on the time period one's has worked in an organization extra time rather than the regular working hours.

$>$ Majority of the respondents had not perform the tasks effectively, so the study recommends that Ministry of Health and management of Mizan Tepi University Teaching Hospital should prioritizes the implementation of a performance management system to measure the performance of employees and that should be used as a tool to award the compensation packages to employees.

$>$ The study recommend that management in Mizan Tepi university teaching hospital should implement incentive pay compensation programs such as allowances, paying overtime properly, as well as insurance, retirement benefit and flexible timing in addition to five elements of compensation( basic salary, bonus, 
house rent allowance, overtime policy and leave policy), this would motivate and improve employee commitment influencing employee performance.

$>$ To provide fair and equitable compensation to the job is better way for the organization because of the proper compensation are useful for acquiring qualified personnel, to retain present employees, to ensure equity and to retain desired behavior in the organization.

\section{Referance}

Armstrong, M. (2010). Strategic Human Resource Management: A Guide to Action Philadelphia: Kogan Page Publishers.

Bhattacherjee, A. (2012). Social Science research principle, methods and practices.

Catherine, N, k. (2018). Compensation system and employee performance (Empirical Evidence from micro finance institution Kenya).

Coetzee, O. (2003). The Relationship between Personality Variables and Work Performance of Credit Controllers in a Bank. Pretoria.

Kothari, C. R. (2004). Research Methodology: Methods and Techniques (2nd revised ed.). India: New Age International Publishers.

Nelson. W, \& Gary. S., (2012). The use of performance measures: case studies from the microfinance sector in Kenya. Qualitative Research in Accounting \& Management, 9(1), 44-65.

Odunlami, I. B., \& Matthew, A. O., (2014). Compensation Management and Employees Performance in the Manufacturing Sector.

Porgamit, N. \& Veum, F. C., (2010). Effect of Rewards on Employee Performance in Organizations: A Study of Selected Commercial Banks in Awka Metropolis.

Pearce, L. (2010). Managerial compensation based on organization performance, Journal of industrial Relation, $52: 3-28$.

Resick. G. (2007). The Measurement of Antecedents of affective, Continuance and normative commitment to the organization. Journal of Occupational Psychology, 63-68. 